\title{
Predictors of risk in patients with unstable angina admitted to a district general hospital
}

\author{
Jeremy J Murphy, Patricia A Connell, John R Hampton
}

\begin{abstract}
Objective-To observe the long-term prognosis of patients with unstable angina and select simple criteria to identify high and low risk subgroups.

Design-A six month prospective survey with three year follow up.

Setting-One eleven bed coronary care unit.

Patients-All patients admitted with chest pain in whom no infarct was confirmed by subsequent electrocardiographic or enzyme changes and for whom no alternative cause of chest pain was found were studied. Unstable angina was also diagnosed if there was evidence of myocardial ischaemia in the form of previous effort angina, previous myocardial infarction, or if transient electrocardiographic changes accompanied the pain. When none of the above were present, chest pain without a known cause, was diagnosed.
\end{abstract}

Interventions-No routine intervention. Angiography and revascularisation for persistent symptoms despite medical treatment.

Outcome measures-Death or nonfatal infarction.

Results-In the 141 patients with unstable angina there were eight deaths and five non-fatal infarctions during the first eight weeks. Symptoms of increasing angina before admission were similar in all three groups and did not help predict early complications. Recurrence of pain in hospital, a rise in cardiac enzymes to less than twice the upper limit of normal, and transient electrocardiographic changes were all associated with an increased risk of early events. The presence of either abnormal enzyme activity or more than five episodes of pain in hospital identified a group of 49 in whom 11 of the 13 early events occurred. After three years, 29 of the 141 patients had died and eight had had infarctions (overall event rate $26 \%$ ). Seventeen had undergone revascularisation (12\%) and $51(36 \%)$ were on antianginal treatment. Thirty six $(26 \%)$ were still alive, without new myocardial infarction, and were free of angina. In the 29 patients with chest pain without a known cause there were no early events and only one non-fatal infarction during the three year follow up.

Conclusion-When patients are admitted to the coronary care unit with chest pain not due to myocardial infarction, the history, electrocardiography and measurement of cardiac enzymes are sufficient to identify high and low risk subgroups.

Cardiologists in regional centres tend to see unstable angina as an emergency situation requiring angiography and intervention, even though there is little evidence that such action improves prognosis. The perspective from a district general hospital is, however, completely different. For more than half the patients admitted with suspected myocardial infarction the diagnosis is not confirmed and many of these patients could by some definitions be diagnosed as having unstable angina. These patients usually require only a very brief stay in hospital, and there are no immediate clinical problems in most of them. Emergency referral to a regional centre because of persistent angina when at rest is a rare event.

In 1986, after Cairns et al had confirmed the benefit of aspirin in unstable angina, ${ }^{1}$ a finding previously reported in the Veterans' Administration study, ${ }^{2}$ we prospectively followed up all patients admitted to our coronary care unit in a six month period with the aim of finding the proportion of patients who could be considered to have unstable angina, and of identifying high and low risk subgroups. We wanted to see how many of these patients progressed over a fairly long period, and we aimed to collect data that would be useful for the design of later trials. A subsidiary intention was to see how quickly aspirin would become part of routine clinical treatment in a unit where patients are looked after by general physicians on emergency intake.

The subgroups defined by Conti et alnamely angina of recent onset, angina of increasing severity, and angina at rest-are clearly not of great value to patients in hospital, almost all of whom will have had persistent pain when at rest. ${ }^{3} \mathrm{We}$ therefore set out with no preconceived definition of unstable angina, but identified patients who needed admission because of suspected ischaemic chest pain but who were found not to have had a myocardial infarction.

\section{Patients and Methods}

Between 1 January and 30 June 1986 all admissions to the coronary care unit at University Hospital, Nottingham, were studied. The 11 bed unit receives patients in the care of four 
general medical firms, one of which has an interest in cardiology. While in hospital, patients remain under the control of the admitting medical firm who determine management.

University Hospital shares with Nottingham City Hospital a catchment population of roughtly 650,000 . Referrals from general practice are divided between the two hospitals and University Hospital also receives all admissions from Nottingham's only accident and emergency (A and E) department. It is our policy that whenever possible, patients with suspected myocardial infarction are admitted to the coronary care unit, although this sometimes depends upon the availability of beds and the relative clinical needs of individual patients. The number of patients admitted to medical or geriatric wards with suspected infarction (all patients in whom cardiac enzymes were measured) was obtained from the Nottingham Heart Attack Register (Gray D, personal communication).

Patients admitted to the coronary care unit were interviewed by questionnaire within 24 hours of arrival, except in the case of early death or self discharge when information was obtained from the admission notes. Details of the presenting complaint and cardiac history were recorded. A modified Rose questionnaire was used to identify angina after effort and any change in symptoms within the previous four weeks was noted. ${ }^{4}$ Angina was considered to be more frequent if it occurred at least twice as often as before and changes in the character of the pain were also recorded. In all cases, cardiac enzymes (aspartate aminotransferase and hydroxybutyrate dehydrogenase) and standard 12 lead electrocardiograms were recorded over three consecutive days, other investigations being performed at the discretion of the individual medical firms.

Patients with chest pain or tightness of at least 15 minutes duration in the 48 hours preceding admission were allocated to one of five diagnostic groups after the results of cardiac enzyme activity measurement and electrocardiograms. When cardiac pain was due to a primary cause other than coronary artery disease, such as an arrhythmia, cardiomyopathy, or valve disease, secondary angina was diagnosed.

The diagnosis of acute myocardial infarction was made when two of three criteria were fulfilled: (a) chest pain for at least 15 minutes; (b) increase in at least one cardiac enzyme above twice the upper limit of normal in the absence of an obvious non-cardiac cause, and (c) new electrocardiographic changes characteristic of infarction; these were pathological $Q$ waves (at least $40 \mathrm{~ms}$ duration and $1 / 3$ of the $R$ wave height) in two adjacent leads, a dominant $\mathbf{R}$ wave in V1 and V2 ( >1 mm and larger than the $S$ wave), a new bundle branch block or ST-T wave changes persisting for more than three days (non- $Q$ wave infarction). Patients with electrocardiographic changes lasting less than 72 hours who did not have a diagnostic enzyme rise were labelled as unstable angina, as described later. The acute myocardial infarction group also included patients presenting with breathlessness, collapse, or arrhythmia without chest pain, in whom both electrocardiographic and enzyme criteria were filfilled.

When, in the opinion of the attending medical firm, features of the history, examination, or subsequent investigations were sufficient to make a specific non-cardiac diagnosis then non-cardiac pain was diagnosed.

After the exclusion of infarction, the label of unstable angina was given if the admission symptoms were supported by evidence of ischaemic heart disease in the form of $(a)$ effort related angina as defined by the Rose questionnaire in the preceding four weeks; (b) a documented previous infarction (using the criteria given previously); or (c) ST-T wave changes in association with pain lasting less than 72 hours.

Three subgroups of unstable angina were selected in advance as they were considered to represent levels of increasing probability that the presenting symptoms reflected myocardial ischaemia. Patients in group 1 had a history of effort related angina but had had no evidence of previous infarction and no electrocardiographic changes with the presenting pain. Patients in group 2 had had a previous infarction but had no new changes on the electrocardiogram. Group 3 contained patients with ST$T$ wave changes in association with the admission pain but which persisted for less than 72 hours and who did not have a rise in enzyme activity diagnostic of infarction. Some of the patients in group 3 had also suffered a previous infarction and a proportion of patients in groups 2 and 3 had already had effort related angina.

The remaining patients were diagnosed as having chest pain without a known cause. This group had no history of angina or infarction, normal electrocardiograms and cardiac enzymes, and no features to support a noncardiac diagnosis. Within two weeks of admission these patients underwent a symptom limiting treadmill exercise test according to the Bruce protocol. A positive result was defined as chest pain in association with $1 \mathrm{~mm}$ horizontal or downsloping ST segment depression, measured at $80 \mathrm{~ms}$ after the J point, or $2 \mathrm{~mm}$ of ST segment depression without pain.

With the exception of non-cardiac pain the above diagnostic labels were independent of the attending physicians. For the purposes of the study, patients in whom acute myocardial infarction was diagnosed were only followed up until discharge from hospital. All patients in the three subgroups of unstable angina and those with chest pain without a known cause were followed up for at least three years after discharge for the development of cardiac events. This follow up was independent of the physicians involved with management. During the three year period, myocardial infarction was diagnosed by the criteria as already described and cause of death was ascertained from death certificates, supported by a review of hospital and general practice notes. After three years a second Rose questionnaire was used to examine the prevalence of effort related angina in all survivors. 
STATISTICAL ANALYSIS

Survival curves were constructed for cardiac death and non-fatal infarction combined. The Lee-Desu method was used for statistical comparisons. Contingency tables were analysed by $\chi^{2}$ test and parametric data by analysis of variance with logarithmic transformation as necessary.

\section{Results \\ ALL CORONARY CARE UNIT ADMISSIONS}

Over the six month study period there were 809 admissions to the coronary care unit, 530 of which were either associated with chest pain, or acute myocardial infarction was suspected for other reasons. Information about 10 patients was collected solely from the case records and the remainder were interviewed within 24 hours. Acute myocardial infarction was the final diagnosis in 304 admissions (285 patients), unstable angina in 149 admissions (141 patients), and chest pain without a known cause in 31 ( 29 patients). In 32 patients admitted with pain due to cardiac ischaemia, a primary cause other than coronary artery disease was diagnosed, such as aortic stenosis, an arrhythmia, or severe anaemia. Non-cardiac pain was the diagnosis in the remaining 14 ; there were six patients with chest infection and pleurisy, two with pulmonary embolism, three with oesophagitis, and one each with aortic dissection,

Table 1 Characteristics and in hospital outcome of consecutive patients admitted to the coronary care unit according to final diagnosis

\begin{tabular}{|c|c|c|c|c|c|c|}
\hline \multirow{2}{*}{$\begin{array}{l}\text { No of admissions } \\
\text { Age (y, mean (range)) } \\
\% \text { Men } \\
\text { Smokers (\%) } \\
\text { Pain for }>30 \text { min (\%) } \\
\text { Previous AMI (\%) } \\
\text { CCU, stay in days (mean } \\
\text { (range)) }\end{array}$} & \multicolumn{2}{|c|}{$A M I(n=304)$} & \multicolumn{2}{|c|}{$\begin{array}{l}\text { Unstable angina } \\
(n=149)\end{array}$} & \multicolumn{2}{|c|}{$C P ? C(n=31)$} \\
\hline & $\begin{array}{r}60 \\
232 \\
223 \\
294 \\
78\end{array}$ & $\begin{array}{l}(32-83) \\
(76) \\
(66) \\
(97) \\
(26)\end{array}$ & $\begin{array}{r}58 \\
112 \\
75 \\
120 \\
80\end{array}$ & $\begin{array}{l}(33-82) \\
(75) \\
(50) \\
(80) \\
(54)\end{array}$ & $\begin{array}{l}49 \\
24 \\
20 \\
22 \\
-\star\end{array}$ & $\begin{array}{l}(35-74)^{\star} \\
(77) \\
(69) \\
(80)^{\star}\end{array}$ \\
\hline $\begin{array}{l}\text { (range)) } \\
\text { Hospital stay in days (mean } \\
\text { (range)) } \\
\text { Death }(\%)\end{array}$ & $\begin{array}{r}8 \\
39\end{array}$ & $\begin{array}{l}(1-56) \\
(13)\end{array}$ & $\begin{array}{l}5 \\
3\end{array}$ & $\begin{array}{l}(1-26) \\
(2)\end{array}$ & $\begin{array}{l}3 \\
0\end{array}$ & $(1-8)^{\star}$ \\
\hline
\end{tabular}

AMI, acute myocardial infarction, CP?C, chest pain without a known cause; CCU, coronary care unit.

^Analysis of variance, $p<0.01$

Table 2 Pre-admission characteristics of the three groups with unstable angina

\begin{tabular}{llll}
\hline & $\begin{array}{l}\text { Angina only } \\
(n=35)\end{array}$ & $\begin{array}{l}\text { Previous } A M I \\
(n=39)\end{array}$ & $\begin{array}{l}S T \text { - } \text { changes } \\
(n=67)\end{array}$ \\
\hline Age (y, mean (range)) & $56(34-82)$ & $59(44-77)$ & $59(33-76)$ \\
$\%$ Men & $23(66)$ & $31(79)$ & $50(75)$ \\
Smoker (\%) & $11(31)$ & $18(46)$ & $35(52)$ \\
Previous AMI (\%) & 0 & $39(100)$ & $38(57)$ \\
\hline
\end{tabular}

AMI, acute myocardial infarction.

Table 3 The frequency and change of angina symptoms over the preceding four weeks in the three unstable angina groups

\begin{tabular}{|c|c|c|c|c|}
\hline \multirow[b]{2}{*}{$\begin{array}{l}\text { Effort related angina } \\
\text { Onset in previous four weeks } \\
\text { Pain at rest } \\
\text { Doubled angina frequency } \\
\text { Restricting activity } \\
\text { More intense pain } \\
\text { Longer episodes } \\
\text { More GTN use }\end{array}$} & $\begin{array}{l}\text { Angina only } \\
(n=35) \text { No (\%) }\end{array}$ & $\begin{array}{l}\text { Previous } A M I \\
(n=39) \text { No }(\%)\end{array}$ & \multicolumn{2}{|c|}{$\begin{array}{l}S T-T \text { changes } \\
(n=67) \mathrm{No}(\%)\end{array}$} \\
\hline & $\begin{aligned} 35 & (100) \\
2 & (6) \\
20 & (57) \\
13 & (37) \\
17 & (49) \\
15 & (43) \\
13 & (37) \\
11 & (31)\end{aligned}$ & $\begin{aligned} 24 & (61) \\
2 & (6) \\
28 & (72) \\
17 & (44) \\
18 & (46) \\
16 & (41) \\
16 & (41) \\
10 & (26)\end{aligned}$ & $\begin{array}{r}35 \\
5 \\
47 \\
31 \\
30 \\
29 \\
36 \\
18\end{array}$ & $\begin{array}{l}(52) \\
(7) \\
(70) \\
(46) \\
(45) \\
(43) \\
(52) \\
(27)\end{array}$ \\
\hline
\end{tabular}

GTN, glyceryl trinitrate; AMI, acute myocardial infarction. pancreatitis, and thoracic root pain. Table 1 shows the characteristics and in hospital clinical course of patients with myocardial infarction, unstable angina, and chest pain without a known cause.

During the same period, 356 patients in whom cardiac enzymes were measured were admitted to medical wards, rather than to coronary care. These patients were not followed up for the purposes of this study, but in general they tended to be older and the range of final diagnoses was much wider. There were 73 deaths in hospital within this group.

Twenty four of the 29 patients with chest pain without a known cause underwent exercise testing and there was only one positive result. This patient developed $2 \mathrm{~mm}$ ST segment depression in leads V4-V5 during stage IV of the Bruce protocol that was not associated with chest pain; she remained pain free and event free for the whole of the three year follow up. The five patients who did not undergo an exercise test were unable or unwilling to walk on the treadmill. Over three years, within the whole group, there was only one cardiac event, a non-fatal infarction. This patient had undergone exercise testing after his index admission, during which he had reached stage $V$ without chest pain or electrocardiographic changes and he had a normal blood pressure response. After three years, three of the remaining 27 had angina as indicated by a positive Rose questionnaire.

\section{PATIENTS WITH UNSTABLE ANGINA}

Eight of the patients with unstable angina were admitted twice during the six month study period, but survival data were only analysed for the first admission. One hundred and forty one patients with unstable angina therefore formed the basis of this study. These patients were divided into the three groups defined above: 35 patients gave a history of effort related angina as defined by a positive Rose questionnaire, but had no electrocardiographic abnormalities at any time (group 1), 39 patients had a documented previous myocardial infarction, but no new electrocardiographic changes (group 2), and in 67 there were transient ST-T wave changes accompanying pain (group 3). Thirty eight patients in group 3 had had a previous myocardial infarction as well as transient ischaemic changes.

\section{Pre-admission characteristics}

Table 2 shows the age, sex, smoking habit, and frequency of previous myocardial infarction in the three groups of patients with unstable angina. Table 3 shows the characteristics of the anginal pain of these patients during the four weeks before admission. Symptoms of worsening angina were equally common in the three groups, and no featues in the history served to distinguish them.

\section{Early complications}

There were three deaths in hospital in the unstable angina group (at days 7, 9, and 24), each resulting from myocardial infarction and giving a mortality of $2 \%$ in hospital. The 
Figure 1 Event free curves (no cardiac death or non-fatal infarction for patients in the three unstable angina groups. The survival curves of patients with previous acute myocardial infarction (AMI) or acute infarction ( $A M I$ ) or acute
$S T-T$ changes did not differ and no events occurred in the group with effort related angina only $(p<0.001)$.

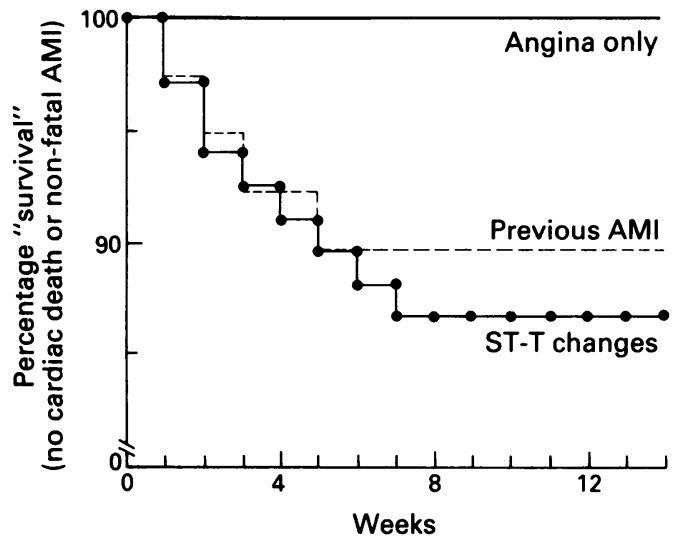

remaining patients were considered to have settled on medical treatment so none underwent immediate angiography. Figure 1 shows the event free survival curves for all the patients (including the early deaths) in the three diagnostic categories of unstable angina. In group 1 there were no cases of myocardial infarction or cardiac death during the first four months. In groups 2 and 3 cardiac events occurred at a constant rate for up to eight weeks after admission, so this can be regarded as the period of acute instability, which we selected for the study of early events. During this eight week period eight deaths and five non-fatal infarctions occurred in the 141 patients with unstable angina (event rate $9 \%$ ). There were three deaths with one non-fatal infarction in the 39 patients in group 2 (event rate $10 \%$ ) and five deaths with four non-fatal infarctions in the 67 patients in group 3 (event rate $13 \%$ ).

Data relating to the pre-admission and in hospital course of all the patients with unstable angina were reviewed in an attempt to identify factors that might select patients at high risk of developing an early cardiac event. After a review of previous studies ${ }^{25-15}$ the factors selected were age, the duration of preceding angina, change in symptoms before admission, heart failure (the need for $40 \mathrm{mg} /$ day or more of frusemide), the presence of electrocardiographic abnormalities, direction and site of ST segment shift, and recurrence of pain in hospital. We also examined the influence of rises in minor enzyme levels not diagnostic of infarction.

Those with and without an early event were of comparable mean age ( $57 v 59$ years) and most were men $(10(77 \%) v 71(76 \%))$. Nine $(69 \%)$ of the 13 with an early cardiac event had a documented previous infarction compared

Table 4 The frequency and change of angina symptoms over the preceding four weeks in patients with unstable angina, and a documented previous infarction or transient $E C G$ changes, according to whether or not they developed cardiac death or non-fatal infarction over the next eight weeks

\begin{tabular}{|c|c|c|c|}
\hline & $\begin{array}{l}\text { Death or } A M I \\
(n=13) \text { No }(\%)\end{array}$ & $\begin{array}{l}N o n \\
(n=\end{array}$ & $=93)$ No $(\%)$ \\
\hline $\begin{array}{l}\text { Effort related angina } \\
\text { Onset in previous four weeks } \\
\text { Pain at rest } \\
\text { Doubled angina frequency } \\
\text { Restricting activity } \\
\text { More intense pain } \\
\text { Longer episodes } \\
\text { More GTN use }\end{array}$ & $\begin{array}{ll}8 & (62) \\
1 & (8) \\
7 & (54) \\
7 & (54) \\
6 & (46) \\
6 & (46) \\
7 & (46) \\
4 & (31)\end{array}$ & $\begin{array}{r}51 \\
6 \\
68 \\
41 \\
42 \\
39 \\
45 \\
24\end{array}$ & $\begin{array}{l}(56) \\
(6) \\
(73) \\
(44) \\
(45) \\
(42) \\
(48) \\
(26)\end{array}$ \\
\hline
\end{tabular}

No differences achieved statistical significance. AMI, acute myocardial infarction with $68(73 \%)$ of the remainder. The nature and duration of symptoms of angina before hospital admission were similar in the two groups (table 4) as was the frequency of diuretic use (overall frequency $34 \%$ ). The site of ST segment or $\mathrm{T}$ wave changes (inferior, anterior, or lateral) in group $3 \mathrm{had}$ no influence on the development of subsequent events. As there were only six patients with ST segment elevation, numbers were insufficient to compare those with ST segment elevation and depression. Sub-dividing group 3 (patients with transient electrocardiographic changes) into those with and without a previous myocardial infarction did not identify a high risk group, as there were six events (16\%) among the 38 patients with a previous infarction compared with three $(10 \%)$ among the 30 who had had no previous infarction.

Recurrence of pain in hospital, defined as a need for treatment with glyceryl trinitrate or opiates, did to some extent predict patients at increased risk. Among the 106 patients in groups 2 and 3, 51 had no recurrence of pain after admission and within this subgroup there were five $(11 \%)$ who had an early myocardial infarction or cardiac death. There were four $(11 \%)$ events in the 37 patients who had up to five episodes of recurrent pain and four $(22 \%)$ events in the 18 patients who had more than five episodes of pain during their admission.

Three features were recognised as helping to identify patients at increased risk of early cardiac events: recurrent pain, reversible electrocardiographic changes, and a rise in cardiac enzymes to less than twice the upper limit of normal. Eight of the 13 early events occurred in 35 patients with minor enzyme rises (sensitivity $62 \%$, specificity $71 \%$, positive predictive accuracy $23 \%$ ). The presence of reversible electrocardiographic changes identified 67 patients in whom nine early events occurred (sensitivity $69 \%$, specificity $38 \%$, and positive predictive accuracy $13 \%$ ). Any recurrence of pain was associated with eight events in $\mathbf{5 5}$ patients (sensitivity $62 \%$, specificity $49 \%$, positive predictive accuracy $15 \%$ ). Selecting patients with more than five attacks of pain in hospital identified 18 patients in whom four events occurred (sensitivity $31 \%$, specificity $85 \%$, positive predictive accuracy $22 \%$ ).

Table 5 shows the value of choosing either of two features as a means of predicting patients at risk of death or myocardial infarction over the subsequent eight weeks. Any recurrence of pain in hospital with either reversible electrocardiographic changes or a minor enzyme rise gave a sensitivity of $92 \%$ but the specificity was poor. The selection of patients with either a minor enzyme rise or more than five attacks of pain in hospital gave a slightly lower sensitivity but greatly improved specificity.

\section{Treatment given}

Patients with chest pain without a known cause were usually given no treatment once the initial pain had settled, and those with only a history of angina (group 1) were discharged on antianginal treatment as considered appropriate by the attending firm. Forty nine (46\%) of the 106 
Table 5 Sensitivity, specificity, and positive predictive accuracy when transient electrocardiographic changes $(S T-T)$, recurrence of pain, and minor enzyme rise are combined to identify patients at risk of early cardiac events $(n=106)$

\begin{tabular}{llllll}
\hline & $\begin{array}{l}\text { No } \\
\text { Selected }\end{array}$ & Events & $\begin{array}{l}\text { Sensitivity } \\
(\%)\end{array}$ & $\begin{array}{l}\text { Specificity } \\
(\%)\end{array}$ & $\begin{array}{l}\text { Predictive accuracy } \\
(\%)\end{array}$ \\
\hline ST-T or any further pain & 100 & 12 & 92 & 5 & 12 \\
ST-T or >5 attacks & 74 & 11 & 85 & 33 & 15 \\
ST-T or minor enzyme rise & 80 & 10 & 77 & 25 & $12 \cdot 5$ \\
Minor enzyme rise or >5 attacks & 54 & 11 & 85 & 54 & 20 \\
Minor enzymes or any further pain & 88 & 12 & 92 & 18 & 14 \\
\hline
\end{tabular}

Figure 2 Long term curves for patients with chest pain without a chest pain without a the three unstable angina groups. Patients with angina only (group 1) and CP?C had a similar prognosis. The survival curves for patients with previous acute myocardial infarction ( $A M I)$ or reversible $S T-T$ changes differ but were both significantly worse than group 1 and $C P$ ? $C$ $(p<0.001)$ (groups 2 and 3) did no

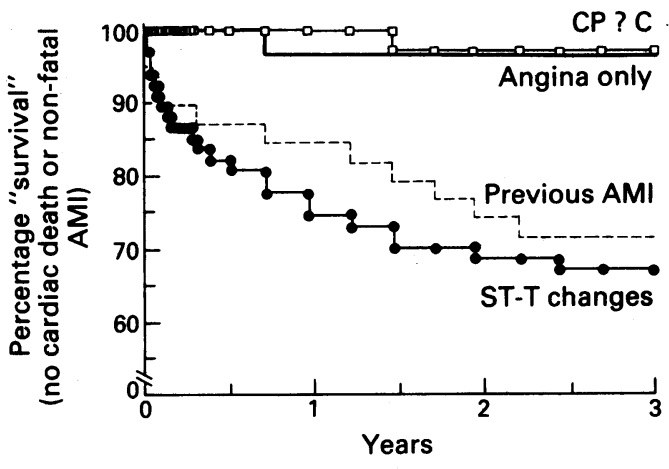

patients with a previous myocardial infarction or with transient electrocardiographic changes (groups 2 and 3 ) were treated with $\beta$ blockers, $27(25 \%)$ with calcium antagonists, and 49 $(46 \%)$ with long acting nitrates. Twelve patients were given three anti-anginal drugs (one from each therapeutic class), 24 were given two, and 41 were given monotherapy. Twenty nine patients were given no angina prophylaxis although most received sublingual nitrates. Only one patients was treated with aspirin and none received thrombolytic therapy or intravenous heparin. The treatment given did not appear to influence the subsequent development of serious cardiac events.

During the eight weeks after discharge, two of the 35 patients with angina only (group 1) had coronary artery bypass graft surgery, as did three of the 67 patients with transient electrocardiographic changes (group 3). In each case the operation was performed because of persistent angina despite maximum medical therapy. No patient in group 2 was considered to need surgery during the first eight weeks. No patients were treated by percutaneous transluminal angioplasty.

Three year follow up

Figure 2 shows the long term event free survival curves for the patients with chest pain without a known cause and for those in the three different categories of unstable angina. Table 6 separates the different types of cardiovascular event, and shows the morbidity among the different groups. Patiens in group 1

Table 6 The state of patients in the unstable angina groups three years after admission

\begin{tabular}{|c|c|c|c|c|c|}
\hline \multirow[b]{2}{*}{$\begin{array}{l}\text { Cardiac death } \\
\text { Non-cardiac death } \\
\text { Non-fatal AMI } \\
\text { CABG or angioplasty } \\
\text { Angina on medical treatment } \\
\text { No angina, events, or surgery }\end{array}$} & $\begin{array}{l}\text { Angina only } \\
(n=35) \text { No (\%) }\end{array}$ & \multicolumn{2}{|c|}{$\begin{array}{l}\text { Previous } A M I \\
(n=39) \text { No }(\%)\end{array}$} & \multicolumn{2}{|c|}{$\begin{array}{l}S T-T \text { changes } \\
(n=67) \text { No }(\%)\end{array}$} \\
\hline & $\begin{aligned}-1 & (3) \\
1 & (3) \\
4 & (11) \\
16 & (46) \\
13 & (37)\end{aligned}$ & $\begin{array}{r}3 \\
7 \\
12 \\
8\end{array}$ & $\begin{array}{l}(8) \\
(18) \\
(31) \\
(21)\end{array}$ & $\begin{array}{r}18 \\
1 \\
4 \\
6 \\
23 \\
15\end{array}$ & $\begin{array}{l}(27) \\
(1) \\
(6) \\
(9) \\
(34) \\
(22)\end{array}$ \\
\hline
\end{tabular}

CABG, coronary artery bypass grafting; AMI, acute myocardial infarction. (angina only) had a similar survival pattern to patients with chest pain without a known cause. After three years, $16(46 \%)$ of those who had been admitted with angina still had this complaint, but $13(37 \%)$ were completely free both of events and angina.

In groups 2 and 3, the initial high event rate in the first two months decreased, but events continued to occur over the whole three year peiod. Only eight $(21 \%)$ of the 39 patients who had had a previous infarction (group 2) and 15 $(22 \%)$ of the 67 patients with reversible ST-T changes (group 3 ) remained free of symptoms and events after three years. The groups with continued complications tended to be older (mean of $61 v 58$ years) although this did not achieve statistical significance $(p=0 \cdot 11)$.

\section{Discussion}

Acute coronary insufficiency was described by Master $e t$ al in 1947 as a condition in which the pattern of angina changed abruptly and which was associated with episodes of pain lasting 30 minutes or more. ${ }^{16}$ In 1961 Wood reported 150 cases and found that myocardial infarction occurred within two months in $22 \%$; he believed that anticoagulation reduced this dramatically. ${ }^{17}$ Since then the condition now usually called unstable angina ${ }^{3}$ has received many names, including the intermittent coronary syndrome, acute myocardial ischaemia, pre-infarction angina, impending myocardial infarction, status anginosus, and accelerated angina. ${ }^{18}$ All these names seem to imply a dangerous and changing state, about which something must be done.

After trials with thrombolytic agents, aspirin, $\beta$ blockers, calcium antagonists, and percutaneous transluminal coronary angioplasty (PTCA) the management of patients with acute myocardial infarction has become increasingly well defined, but unstable angina still presents a major problem. Apart from aspirin $^{12}$ and ticlopidine ${ }^{19}$ (which is not available in the United Kingdom), there is no clear evidence on which to base a management policy for such patients, although an overview of $\beta$ blocker trials ${ }^{20}$ and recent studies of heparin suggest benefit. ${ }^{2122}$ A contemporary review recommends aspirin or heparin in combination with a $\beta$ blocker as the first therapeutic option, a calcium antagonist being added if symptoms persist. ${ }^{23}$ For those with recurrent angina, angiography and revascularisation are logical progressions but are not without risk and their effect on the natural history is unknown. ${ }^{24} 25$ In a study in the 1970s that compared early surgery with medical treatment there was little difference in mortality, ${ }^{26}$ but the surgical group 
had a higher rate of early infarction whereas the medical group had a higher rate of late angina, eventually leading to surgery. Although these data are generally interpreted as recommending caution against early intervention, some enthusiasts still recommend angiography and some form of revascularisation for all patients with unstable angina. ${ }^{27}$

Comparisons between the cardiovascular event rates which we found and other published data are difficult because of differences with case selection, and because different durations of follow up have been described. In a community study of patients, not in hospital, with recent onset or worsening of pre-existing angina, the one month and six month cardiac event rates (fatal and non-fatal infarction combined) were $7 \%$ and $13 \% .{ }^{14} 28$ In studies of patients with unstable angina who were admitted to hospital, the rate of fatalities in hospital varied between 1 and $8 \%$, whereas the one year fatality rate was $10-18 \%$. The event rate one month after admission was between 9 and $13 \% .^{891115}$

Control groups from trials of drug treatments give a clearer view of the importance of case selection. In the Canadian study of aspirin and sulphinpyrazone, patients were included if they had a positive Rose questionnaire or transient electrocardiographic changes with pain. ${ }^{1}$ After a mean of 18 months, the event rate in the placebo group was $17 \%$ with $11.7 \%$ deaths. In the Veterans' Administration study of aspirin, entry to the study depended mainly on the patients' history with some more definitive evidence of underlying coronary disease. ${ }^{2}$ The event rate at three months was $10.1 \%$ with $3.3 \%$ deaths. In the ticlopidine study, which included patients with an appropriate history and transient electrocardiographic changes, the event rate at six months in the control group was $13.6 \%$ with $4.7 \%$ deaths. ${ }^{19}$ These results can be compared with our rate of event at two months of $9 \%$ of all patients with unstable angina, $10 \%$ in those with a previous infarction, and $13 \%$ in those with transient electrocardiographic changes. The relatively low event rate in the Veterans' Administration trial probably reflects the inclusion of cases we have identified as low risk, ${ }^{2}$ whereas the patients admitted to the ticlopidine trial were comparable with our high risk group.

Our findings suggest that once two months have elapsed the risk diminishes and is probably similar to that of patients who have survived a myocardial infarction for a similar time. The three year mortality of $25 \%$ in our groups 2 and 3 compares with $33 \%$ in infarct survivors reported by Norris et al. ${ }^{29}$ Our early event rate within the first two months in these groups should also be compared with those shown to have had a myocardial infarction. In second international study of infarct survival (ISIS-2), ${ }^{30}$ Gruppo Italiano per lo Studio della Streptochinasi nell'Infarcto Miocardico (GISSI), ${ }^{31}$ and Anglo-Scandinavian study of early thrombosis (ASSET) ${ }^{32}$ mortality in the placebo group at one month ranged from $9.8 \%$ to $13 \%$; the proportion eventually shown to have a myocardial infarction being variable. At six months $13.1 \%$ of the placebo group in ASSET had died $(17 \cdot 1 \%$ of those with a definite infarction); at one year $18 \%$ of the placebo group in ISIS 2 and $19 \%$ of those in GISSI had died. In all of these studies the nonfatal reinfarction rate was low at 3 or $4 \%$ in the first month, and up to 6 or $7 \%$ in the first six months. Our hospital death mortality rate of $13 \%$ for patients with acute infarction is therefore what would have been expected in the pre-thrombolytic era, and this event rate should be compared with the hospital mortality rate of $3 \%$, a mortality rate at two months of $7.5 \%$, and the three year mortality rate of $25 \%$ for the 106 patients in groups 2 and 3. In these patients the non-fatal reinfarction rate was $5 \%$ at two months.

If we include patients who are admitted to a coronary care unit because of a history suggestive of prolonged ischaemia at rest but who have no other evidence of coronary disease, (chest pain without a known cause group), the outlook is clearly better than it is for patients with myocardial infarction. Patients with only a positive Rose questionnaire as a means of making the diagnosis (our group 1) also have an excellent prognosis so there are high and low risk groups within the overall category of unstable angina. Severi et al found, ${ }^{33}$ as we did, that patients in whom the diagnosis was made simply on the basis of history had an excellent prognosis, and they showed that the subsequent positive exercise test had little relation to the outcome. Heart failure (defined as an increased cardiothoracic ratio ${ }^{1014}$ or raised left ventricular end diastolic pressure ${ }^{5}$ ) identified a higher risk group in some but not all studies. ${ }^{8}$ Recurrence of pain ${ }^{8-11} 15$ and electrocardiographic changes 10121317 have generally been found to identify high risk subgroups, and some authors have also highlighted specific changes on the electrocardiogram. De Servi et $\mathrm{al}^{5}$ found a higher mortality in patients with ST segment depression than with elevation and Sclarovsky et al ${ }^{34}$ highlighted the significance of $T$ wave changes in those with anterior lead horizontal or downsloping ST segment depression. ${ }^{6}$ Left main stem occlusion was present in seven out of 10 of those with $T$ wave inversion and in none of the 21 with upright $T$ waves. ${ }^{33}$ In the study by de Zwaan et al $^{7}$ abnormal ST segments with $\mathrm{T}$ wave inversion in $\mathrm{V} 2$ and $\mathrm{V} 3$ identified patients with a left anterior descending lesion, $83 \%$ of whom had the culprit lesion proximal to the first septal perforator. Both a long history of ischaemic heart disease ${ }^{8}$ and the lack of preceding symptoms ${ }^{911}$ have been suggested as identifying high risk subgroups. Our identification of high risk groups was based simply on history, electrocardiogram, and cardiac enzyme activity results-all of which are routinely collected on coronary care unit admissions-so clearly this is a practical way for physicians in district general hospitals to recognise the high risk patient. But should such patients undergo angiography and revascularisation?

Very few events occur in the low risk groups so it seems reasonable to suppose that the 
beneficial effects of aspirin must depend on a reduced rate of event in what we have called high risk patients. We could therefore assume that treatment with aspirin could have reduced the event rate at two months in this group to perhaps $10 \%$. A clinical trial of any further intervention designed to show, with conventional levels of power and significance $(\alpha=$ $0.05,1-\beta=0.90)$, a further $30 \%$ reduction in events would need to contain 5600 such patients. Assembly of such a trial would, from our experience, require the screening of over 80000 coronary care admissions. It is clearly going to be extremely difficult to establish whether coronary angiography, percutaneous transluminal coronary angioplasty, or coronary artery bypass will reduce the risk of cardiac death or non-fatal infarction in these patients. The morbidity of the condition is substantial, with only a minority of patients remaining event free and free from angina at three years, so a study that included chronic angina as an undesirable outcome would be more feasible.

We thank Dr D Gray for providing data from the Nottingham Heart Attack register and the physicians of University Hospital, Nottingham for permission to study their patients.

1 Cairns JA, Gent M, Singer J, et al. Aspirin, sulphinpyrazone, or both in unstable angina. $N$ Engl J Med 1985; 313:1369-75.

2 Lewis HD Jr, Davis JW, Archibald DG, et al. Protective effects of aspirin against acute myocardial infarction and death in men with unstable angina. Results of a Veterans death in men with unstable angina. Results of a Veterans
Administration Cooperative study. $N$ Engl J Med 1983; Administration

3 Conti CR, Brawley RK, Griffith LS, et al. Unstable angina pectoris: morbidity and mortality in 57 consecutive patients evaluated angiographically. $A m J$ Cardiol 1973;32:745-50.

4 Rose GA. The diagnosis of ischaemic heart pain and intermittent claudication in field surveys. Bull World Health Organ 1962;27:645-58.

5 De Servi S, Ghio S, Ferrario M, et al. Clinical and angiographic findings in angina at rest. Am Heart J 1986;111: 6-11.

6 Sclarovsky S, Davidson E, Strasberg B, et al. Unstable angina: the significance of ST segment elevation or depression in patients without evidence of increased myocardial oxygen demand. Am Heart J 1986;112:463-7.

7 De Zwaan C, Bar FW, Janssen JHA, et al. Angiographic and clinical characteristics of patients with unstable angina showing an ECG pattern indicating critical narrowing of showing an ECG pattern indicating critical narrowing of
the proximal LAD coronary artery. Am Heart J 1989; the proximal

8 Krauss KR, Hutter AM, De Sanctis RW. Acute coronary insufficiency. Course and follow-up. Arch Intern Med 1972;129:808-13.

9 Heng M-K, Norris RM, Singh BN, Partridge JB. Prognosis in unstable angina. Br Heart $J$ 1976;38:921-5.

10 Olson HG, Lyons KP, Aronow WS, Stinson PJ, Kuperus J, Waters $\mathrm{HJ}$. The high-risk angina patient. Identification by clinical features, hospital course, electrocardiography and Technetium-99m stannous pyrophosphate scintigraphy. Circulation 1981;64:674-84.

11 Mulcahy R, Daly L, Graham I, et al. Unstable angina: natural history and determinants of prognosis. $\mathrm{Am} \mathrm{J}$ Cardiol 1981;48:525-8.

12 Langer A, Freeman MR, Armstrong PW. ST segment shift in unstable angina: pathophysiology and association with Cardiol 1989;13:1495-1502.

13 Madsen JK, Thomsen BL, Mellemgaard K, Hansen JF. Independent prognostic risk factors for patients referred independent prognostic risk factors for patients referred confirmed diagnosis. Prognosis after discharge in relation
consection confirmed diagnosis. Prognosis after discharge in relation to medical history and

14 Duncan B, Fulton M, Morrison SL, et al. Prognosis of new and worsening angina pectoris. $B M J 1976 ; 1: 981-5$.

15 Gazes PC, Mobly EM, Faris HM Jr, Duncan RC Humphries GB. Pre-infarction (unstable) anginaprospective study - ten year follow-up. Circulation 1973; 48:331-7.

16 Master AM, Dack S, Grishman A, Field LE, Horn H. Acute coronary insufficiency: an entity. Shock haemorrhage and pulmonary embolism as factors in its production. Journal of the Mount Sinai Hospital 1947;14:8-23.

17 Wood P. Acute and subacute coronary insufficiency. BM 1961;1:1779-82.

18 Anonymous. Intermittent coronary syndrome. BMJ 1973 ; 3:601-2.

19 Balsano F, Rizzon P, Violi F, et al. Antiplatelet treatment with ticlopidine in unstable angina. Circulation 1990; 82:17-26.

20 Yusuf S, Wittes J, Friedman L. Overview of results of randomized clinical trials in heart disease. II. Unstable angina, heart failure, primary prevention with aspirin, and risk factor modification. $J A M A$ 1988;260:2259-63.

21 Theroux P, Ouimet H, McCans J, et al. Aspirin, heparin, or both to treat acute unstable angina. $N$ Engl J Med 1988 319:1105-11.

22 Serneri GN, Gensini GF, Poggesi L, et al. Effect of heparin, aspirin, or alteplase in reduction of myocardial ischaemia in refractory unstable angina. Lancet 1990;i:615-8.

23 Lubsen J. Medical management of unstable angina: what have we learnt from the randomized trials? Circulation 1990;82 (suppl II):1182-7.

24 Naunheim KS, Fiore AC, Arango DC, et al. Coronary artery bypass grafting for unstable angina: risk analysis. $A n n$ bypass grafting for unstable
Thorac Surg 1989;47:569-74.

25 de Feyter PJ. Coronary angioplasty for unstable angina. $A m$ Heart $J$ 1989;118:860-8.

26 Russell RO Jr, Rackley CE, Kouchoukos NT. Unstable angina pectoris: do we know the best management? $\mathrm{Am} J$ Cardiol 1981;48:590-1.

27 Rahimtoola SH. Coronary bypasss surgery for unstable angina. Circulation 1984;69:842-8.

28 Fulton $M$, Lutz $W$, Donald $\mathrm{KW}$, et al. Natural history of unstable angina. Lancet 1972;i:860-5.

29 Norris RM, Caughey DE, Deeming LW, Mercer CJ, Scott PJ. Coronary prognostic index for predicting survival after recovery from acute myocardial infarction. Lancet $1970 ; \mathbf{i i}: 485-8$

30 ISIS-2 (Second International Study of Infarct Survival) Collaborative group. Randomised trial of intravenous streptokinase, oral aspirin, both or neither among 17187 cases of suspected acute myocardial infarction: ISIS-2 Lancet 1988;ii:349-60.

31 Gruppo Italiano per lo Studio della Streptochinasi nell' Infarto Miocardico (GISSI). Long-term effects of
intravenous thrombolysis in acute myocardial infarction: intravenous thrombolysis in acute myocardial infarction:
final report of the GISSI study. Lancet 1987;ii:871-4.

32 Wilcox RG, Von der Lippe G, Olsson CG, Jensen G, Skene AM, Hampton JR. Effects of alteplase in acute myocardia infarction: 6-month results from the ASSET study. Lancet 1990;i:1175-8.

33 Severi S, Orsini E, Marraccini P, Michelassi C, L'Abbate A. The basal electrocardiogram and the exercise stress test in assessing prognosis in patients with unstable angina. Eur Heart J 1988;9:441-6.

34 Sclarovsky S, Rechavia E, Strasberg B, et al. Unstable angina: ST segment depression with positive versus negative $T$ wave deflections-Clinical course, ECG evolution, and angiographic correlation. Am Heart J 1988; 116:933-41. 